\title{
The emergency system for the town of Milano: evaluation of an help point
}

\author{
Isabella Tiziana Steffan ${ }^{\mathrm{a}}$ \\ ${ }^{a}$ Studio Steffan - Progettazione \& Ricerca, Via G.C. Procaccini, 69 - 20154 Milano
}

\begin{abstract}
The article presents a complex work of which the author has been asked by the Municipality of Milan an its Service Company (AEM, now A2A) to apply Ergonomics to evaluate a product designed for asking information and emergency, with particular attention to vulnerable city users.
\end{abstract}

Keywords: emergency system, help point, municipality of Milan, ergonomic evaluation, redesign

\section{Introduction}

The perception of security in big cities is nowadays a crucial issue to society and it is connected to emergency situations.

The Municipal Administration of Milan by its Service Company (AEM, now A2A) have realized a series of remote monitoring and remote assistance systems as tools to monitor the area and to ensure maximum security for visitors and a greater preservation of public property.

The typical station consists of a pedestal SOS point and a camera that allows the local Police Stations to detect abnormal situations in critical areas of the city. The user can ask for help from the SOS point and communicate with the video monitoring system.

The SOS devices are managed round the clock by the Local Police at the local Police Station. All data are recorded and appropriately managed by the Operations Centre of the Police Station, where all information regarding the safety of the municipality and city traffic are dealt with.

The author was asked to test out the user interface, in particular disabled user, of a specific artefact, mainly conceived for emergency calls (2002- 2004). Afterwards, the author has coordinated a multidisciplinary teamwork for the plan of development and diffusion of SOS points in the city of Milan (2005 - 2006).

The main objectives of the work have been firstly the identification of criteria and tools able to detect *the final user's expectations about "SOS column City of Milan", in order to make SOS points more congruent with such expectations before their installation on a large scale, realization and maintenance costs permitting.

Secondly, the objective has been guaranteeing an efficient and sustainable management of the system and training a proper number of operators able answer the requests for help effectively.

\section{Method}

The first prototype, a column with its top characterized by an oblique cut, has been evaluated by experts who have highlighted some necessary modifications for a better usability, also by people with motor disabilities.

In order to evaluate the interface with the user of the pre-series of this artefact, a test has been carried out in the real context of use, with tools and methods peculiar to ergonomics.

Twelve SOS columns have been installed experimentally in the area of Milan Central Station and the following items have been assessed in particular:

- identifiability;

- reachability;

- usability.

\footnotetext{
* Corresponding author e-mail: info@studiosteffan.it
} 
The test has been carried out with a minimum sample of people, with special regard to weak users, representative of a typical user in situation of simulated emergency, because of the decadence of the performance of people under stressing conditions. Among the considered parameters particular importance has been given to spotting and usability speed, crucial factors when the user or others are in danger.

Tests have been carried out according to a program of observation of subjects who had never seen the artefact before and included:

- observation of the way the artefact was recognized;

- direct observation and interview about the user friendliness of the artefact;

- video recording by means of the remote monitoring system.

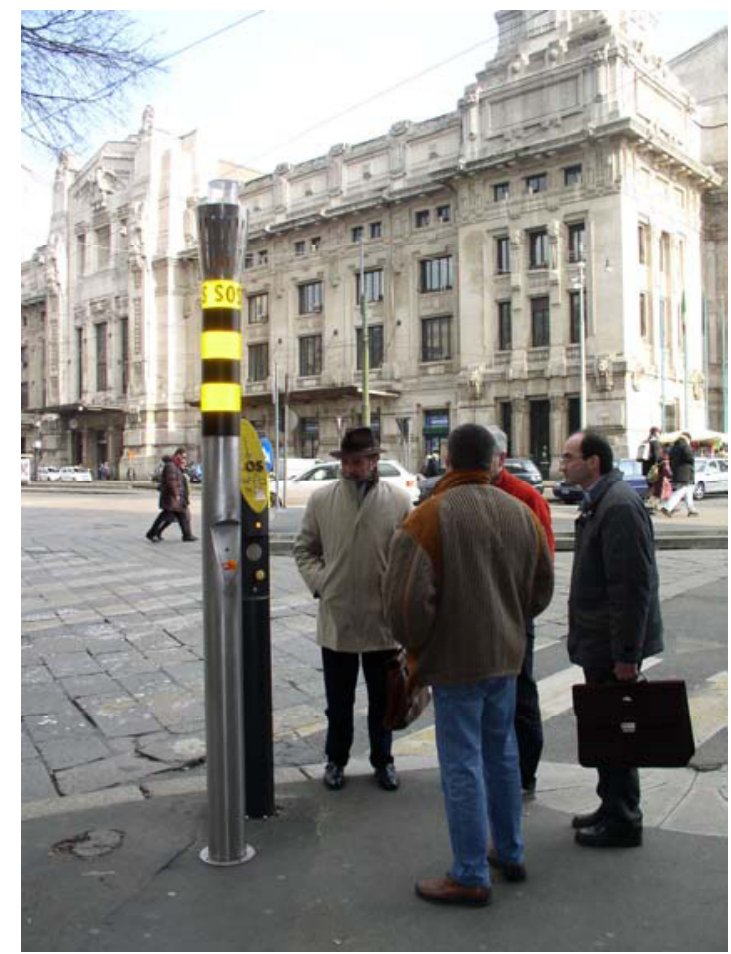

Figure 1

Technical discussion at the Central Station in Milan

People of both sexes have participated (aged 2060 ), some people with motor disabilities and other with visual impairments.

Tests have been recorded with the video monitoring system and the sequences have been carefully evaluated.
The first ergonomic evaluation has highlighted a series of physical and managerial critical points that have driven to the identification of some actions, then implemented in the development plan of the SOS point.

The development plan includes the coordination of different professions, sectors and local companies by means of the following passages:

- the redesign of the SOS column according to requisites emerged during the first analysis carried out with the aid of a designer and companies specialized in the production of industrial artefacts (Figure 1- Figure 2);

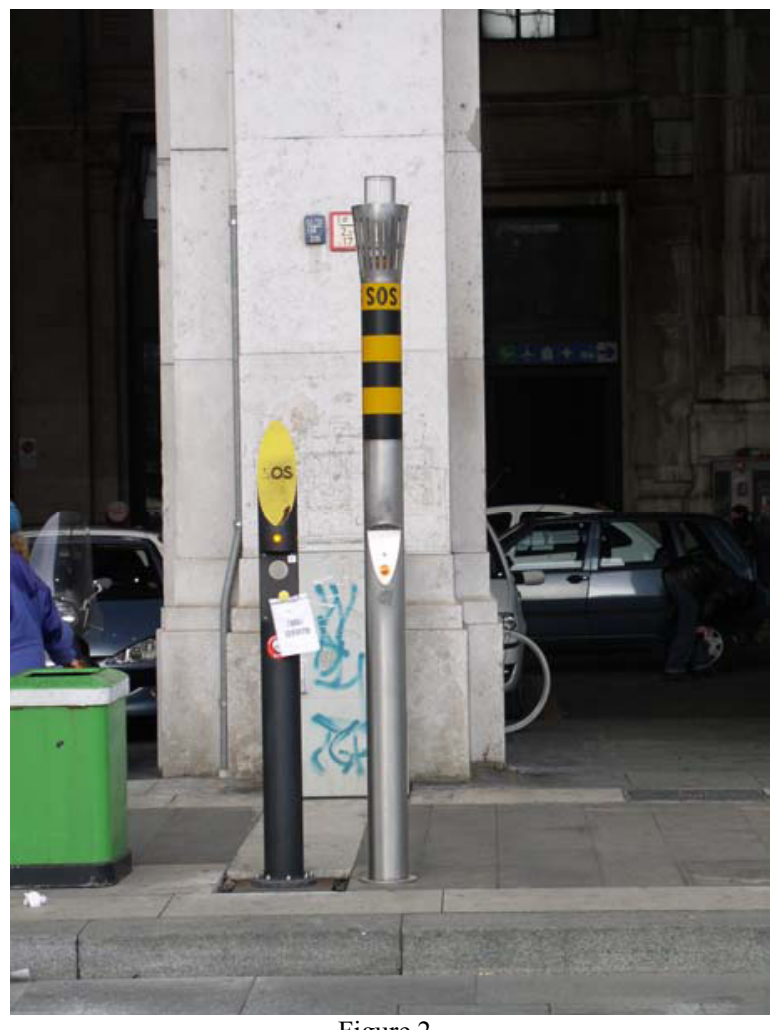

Figure 2

Comparison in the context of use of the two SOS pillars, before their replacement

- check of the possible implementation of the artifact with other technological systems: wireless communication, identification of shots and noises, guide for visually handicapped, display for visual/ communication for foreigners and deaf-mutes, etc.

- realization of 11 new artefacts, that have replaced the previous ones at the Central Station; 
- test to check the effectiveness of the characteristics of the new artefact;

- acceptance of the new artefact;

- a program of first level (for coordinators) and second level (for operators) courses (in collaboration with an expert in emergency psychology) to train operators of the Municipal Police in charge at the Police Station.

- test of effectiveness and efficiency of the system and final evaluations.

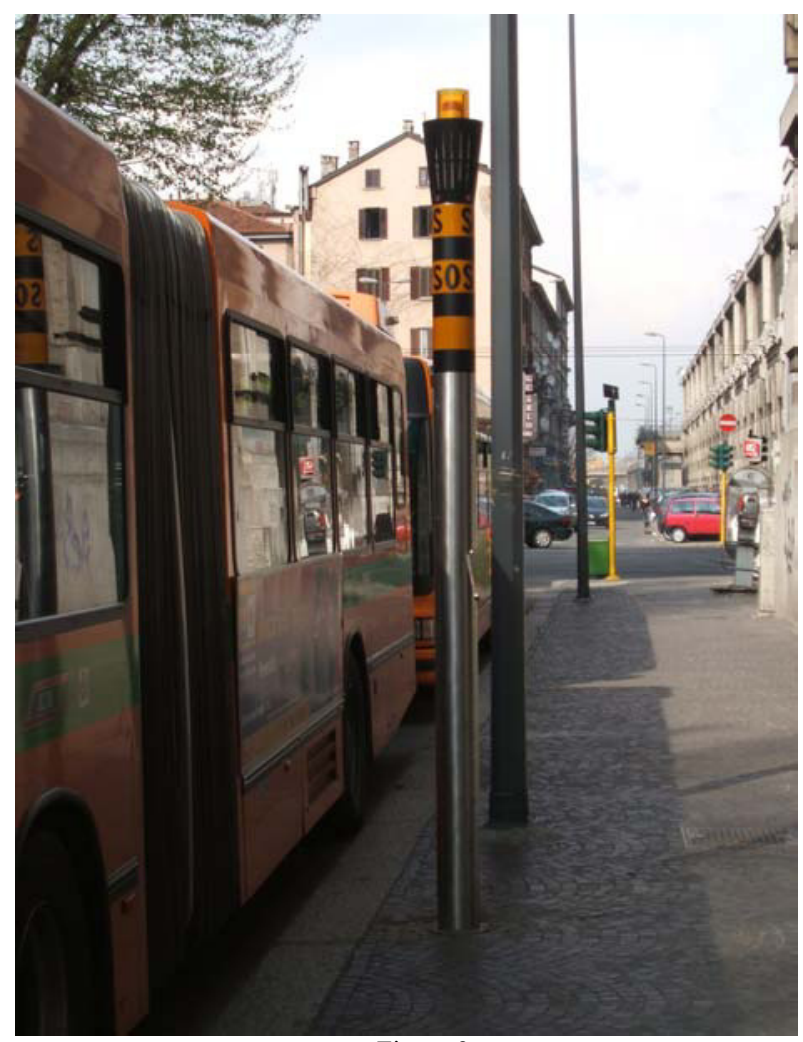

Figure 3

The new SOS pillar near a bus stop in a lateral street of the Central Station

The check test of the artefact modified have been conducted in 2006 with a procedure of observation comparable to the previous one but widened in some aspects as:

- number and characteristics of the population (including young people under 20, old people over 70 years and users with physical and intellectual disability);

- period of observation (adding to daily hours half-light and night hours)
- new characteristics investigated (related to identifiability, visibility, pleasantness and user friendliness).

\section{Results and discussion}

Thanks to ergonomic investigations carried out, the object "SOS column" has been improved, but because of the formal constraints, it is one of the different "poles" on the territory, susceptible to further improvements.

The SOS column has not proved an optimal solution for every urban context. Such points for the distress call, if widely spread on the urban territory, would become an excessive implementation of urban objects (Figure 3 ).

Moreover, it would have an over specialized function if the trained staff is limited.

The tests have highlighted the need of targeted courses for operators who answer the calls. The courses have involved $10 \%$ of the personnel of Municipal Police: they have been trained about technical and maintenance aspects of the system, but above all psychological aspects of their service, that is reassuring interfaces and help in high-anxiety situations, persisting till the solution of the problem.

The results of the research have been: improvement of efficiency of the system, decrease of risks of dissatisfaction of users and operators, and arrangement for the future implementation of the system, coherently with fixed objectives.

The Municipal Administration and its Service Company have demonstrated appreciation for the improvement of ergonomic aspects, for the development of the artefact since the first phases of the design process, for the management of the interface with the user and the coordination of a crucial part of the development of the SOS system: SOS points will be used in a wide security program that will involve all the city of Milan.

This research has been selected and featured on the book ADI DESIGN INDEX 2007, (Enterprise Research area, pages 318-319), published each year by ADI, the Association of Industrial Designers, that identifies the best design projects at national level. These projects, in turn, participate to the three-yearly competition "Compasso d'Oro" (Gold Compass).

Moreover, this work has been presented at the following conferences: "New developments in the usability of products", Study day of the Polytechnic University of Milan, 16 January 2003, "The added 
value of ergonomics. What benefits for enterprises?" SIE Conference, Turin, 10 October 2002

\section{References}

[1] Norman D.A., Lo sguardo delle macchine, Giunti, 1995

[2] Norman, D. A. Emotional Design, Apogeo, Milano, 2004

[3] Sandman, P. M. Responding to community outrage: Strategies for effective risk communication, Fairfax, VA, American Industrial Hygiene Association, 1993.

[4] Slovic, P., Perception of Risk, in «Science», 1987, n. 236, 1987, pp. 280-285.
[5] Steffan I., Un approccio ergonomico per il sistema SOS della Città di Milano: valutazione dell'usabilità di una colonnina SOS e piano di sviluppo per la sua diffusione, in: VIII SIE National Conference proceedings "Ergonomics between innovation and planning, working systems and life styles", Milan, 2006.

[6] Steffan I., "Valutazione dell'usabilità della colonnina SOS per la città di Milano" (Evaluation of the usability of a SOS column for the city of Milan) in Tosi F., Ergonomics \& Design, Polidesign, Milan, 2004, pp 105-110.

[7] Tosi F. (a cura di), Ergonomia \& Design, Polidesign, Milan, 2004 